\title{
Fractional Charging Converter with High Efficiency and Low Cost for Electrochemical Energy Storage Devices
}

Mira Albert, Maria del Carmen; Zhang, Zhe; Jørgensen, Kasper Lüthje; Andersen, Michael A. E.

Published in:

I E E E Transactions on Industry Applications

Link to article, DOI:

10.1109/TIA.2019.2921295

Publication date:

2019

Document Version

Peer reviewed version

Link back to DTU Orbit

Citation (APA):

Mira Albert, M. D. C., Zhang, Z., Jørgensen, K. L., \& Andersen, M. A. E. (2019). Fractional Charging Converter with High Efficiency and Low Cost for Electrochemical Energy Storage Devices. I E E E Transactions on Industry Applications, 55(6), 7461-7470. https://doi.org/10.1109/TIA.2019.2921295

\section{General rights}

Copyright and moral rights for the publications made accessible in the public portal are retained by the authors and/or other copyright owners and it is a condition of accessing publications that users recognise and abide by the legal requirements associated with these rights.

- Users may download and print one copy of any publication from the public portal for the purpose of private study or research.

- You may not further distribute the material or use it for any profit-making activity or commercial gain

- You may freely distribute the URL identifying the publication in the public portal 


\title{
Fractional Charging Converter with High Efficiency and Low Cost for Electrochemical Energy Storage Devices
}

\author{
Maria C. Mira, Zhe Zhang, Senior Member, IEEE, and Kasper L. Jørgensen, Student Member, IEEE and Michael \\ A. E. Andersen, Member, IEEE
}

\begin{abstract}
High efficiency and low cost power converters for interfacing energy storage have become critical in renewable energy systems. In this paper a fractional charging converter (FCC) is proposed to reduce power rating as well as cost of the dcdc converter for hydrogen production by alkaline electrolyzer cells. The FCC configuration only processes the partial power resulting from the voltage difference between the source and the energy storage element. Moreover, the converter employed in such configuration can be either isolated or non-isolated, which simplifies topology selection. An analysis and comparison of two dcdc topologies using a high-frequency transformer based on component stress factor (CSF) is performed to determine the optimal solution for the evaluated application. Based on the results of the CSF analysis, and due to its capability of handling wide input voltage, the isolated full-bridge boost (IFBB) converter is designed, built and tested. Experimental results prove the feasibility of the fractional charging configuration with a reduction of $80 \%$ of the power rating compared to the traditional interconnection, which implies a reduction in cost, weight and an increase in efficiency. The converter's maximum voltage gain achieved is 25 and the highest measured system efficiency is $98.2 \%$.
\end{abstract}

Keywords—energy storage, converter, fractional, electrolysis.

\section{INTRODUCTION}

Electrochemical energy storage is an emerging technology, which can provide high flexibility in terms of energy density and power capacity [1]-[2]. Power-to-X (P2X) is a promising option for storing intermittent sustainable renewables and providing clean energy to residential, industrial, transportation users, etc. For example, alkaline water electrolysis $(\mathrm{H} 2, \mathrm{Al}$ and $\mathrm{Cl})$ have a global capacity $>100 \mathrm{GW}$ and its demand is growing fast in recent years [3]-[5]. The advantages of hydrogen is that it can be produced locally, and it offers high energy density, long-term scalable storage and low environmental impact. However, the cost of the initial investment is high and there are safety considerations. Thus, in order to make electrolysis units practical and economic in renewable energy systems, a complete system powered by renewables, including the renewable power source, electrolyzer, and interfacing power electronic devices, must be effectively integrated and optimized to improve system efficiency as well as reduce cost [6].

The conventional way of interconnecting energy storage systems (ESS) to a dc bus is shown in Fig. 1 (a), where a positive and a negative terminal of a bidirectional dc-dc converter are connected to the ESS, while the other positive and negative terminals of the dc-dc converter connected to a regulated dc bus [7]. With the conventional power conversion system, the dc-dc

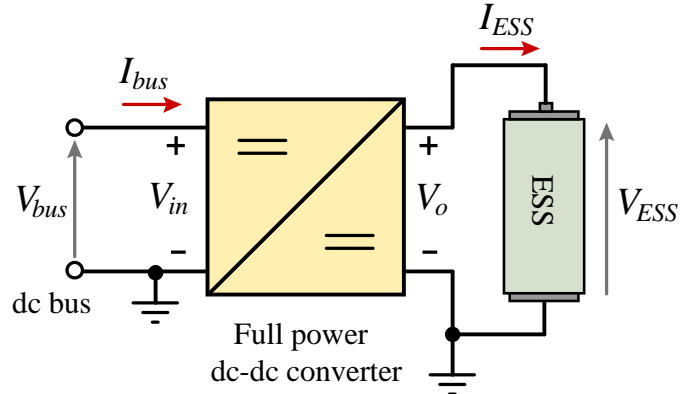

(a)

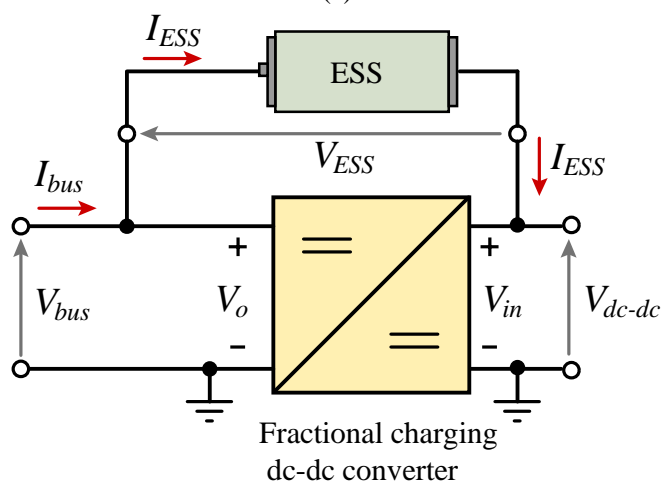

(b)

Fig. 1: Block diagram of dc power conversion system for energy storage systems (ESS). (a) Traditional parallel connection and (b) proposed fractional charging converter (FCC) configuration.

converter must be rated, at least, at the maximum operating power of the ESS. Therefore, efficiency improvement and cost reduction are very challenging to achieve for full power bidirectional dc-dc converters, in particular for electrolyzer or fuel cells with wide input voltage range and high current.

Therefore, fractional or partial power processing technologies were proposed to reduce power rating of power electronic devices and systems in different applications. For instance, in wind generation, the power converters used in doubly fed induction generators (DFIG) are typical $30 \%$ of the generator rated power. This reduces the cost as well as power losses in power electronics [8]. In spacecraft powered by photovoltaics, the idea of the series connection of source and load originated in [9]. The proposed configuration, called series connected boost unit (SCBU), showed numerous advantages compared to the traditional interconnection. High efficiency and high power density can be achieved because the dc-dc converter only processes a fraction of the total power of the system, which results in small, lightweight and low cost power supplies, which 


\section{IEEE TRANSACTIONS ON INDUSTRY APPLICATIONS, VOL. X, NO. X, MONTH YEAR}

in space implementations are extremely important. Depending on the requirements of the application, the series connection of source and load can be performed at the input (input-seriesoutput-parallel ISOP) or at the output of the dc-dc converter (input-parallel-output-series IPOS) [10]. For PV systems, [11] discussed and summarized the various topologies incl. both isolated and non-isolated converters, which can achieved partial power regulation. Reference [12] reviewed the differential power conversion techniques and pointed out that cost reduction and reliability improvement is still challenging. As an example, in [13], a dual active bridge (DAB) converter based universal dc-dc optimizer was proposed by stacking PV strings and batteries, however, without power efficiency reported. Besides PV applications, in [14] and [15], Flyback and DAB converters are used to achieve partial power processing in the applications of wearable devices and fast battery charging, respectively. Nevertheless, due to stacking connection between input and output, isolated topologies must be adopted for such systems in [9], [10] and [13]-[15]. On the other hand, in [16], a $6.7 \mathrm{~kW} \mathrm{dc-}$ dc converter has been implemented which aims to be able to regulate $27 \mathrm{~kW}$ solid oxide electrolysis cells (SOEC) and can achieve a peak system power efficiency of $98.9 \%$. In [17], GaNbased converter with a peak equivalent efficiency of $99.63 \%$ was reported. However, an auxiliary load or source is needed in both [16] and [17] to absorb the circulated power.

In this paper, a directly coupled configuration as shown in Fig. 1 (b), so-called fractional charging converter (FCC) is proposed. The ESS is connected between the positive terminals of the dc-dc converter and dc-bus, and its operation principles have been briefly described in [18]. The input voltage of the dcdc converter $V_{\text {in }}$ is set by the differential voltage between the dc bus and the energy storage system $\left(V_{b u s^{-}} V_{E S S}\right)$. Hence, the dc-dc converter only processes the differential power between the dc bus and the ESS. The smaller the voltage difference, the lower the power that needs to be processed. Moreover, due to the common ground connection, either isolated or non-isolated dc$\mathrm{dc}$ converters can be applied. Based on the theoretical analysis of component stress factor (CSF), an isolated boost converter, which can deal with wide input voltage, is designed and system test is carried out with alkaline electrolyzer cells. The converter achieves the maximum voltage gain of 25 and the highest measured system power efficiency of $98.2 \%$.

This paper is organized as follows. After this introduction, an energy storage system based on alkaline electrolyzer cells (EC) as well as its power converter specifications is introduced in Section II; in Section III CSF compares DAB and isolated fullbridge boost (IFBB) converters; then, the IFBB converter design is presented in Section IV and the experimental results are given in Section V. Finally, Section VI gives a conclusion.

\section{SYSTEM ANALYSIS}

The system being analyzed is an ESS based on alkaline electrolyzer cells (EC); nevertheless, the system configuration can be applied to battery charge systems as well. Fig. 2 shows the electrolyzer stack voltage as a function of the current and Table I presents the specifications of the system in the FCC configuration.

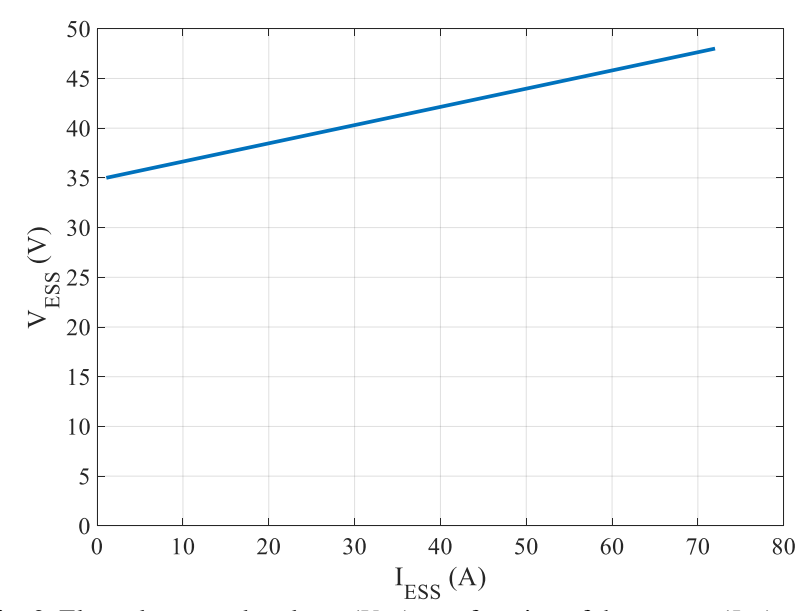

Fig. 2. Electrolyzer stack voltage ( $\left.V_{E S S}\right)$ as a function of the current $\left(I_{E S S}\right)$.

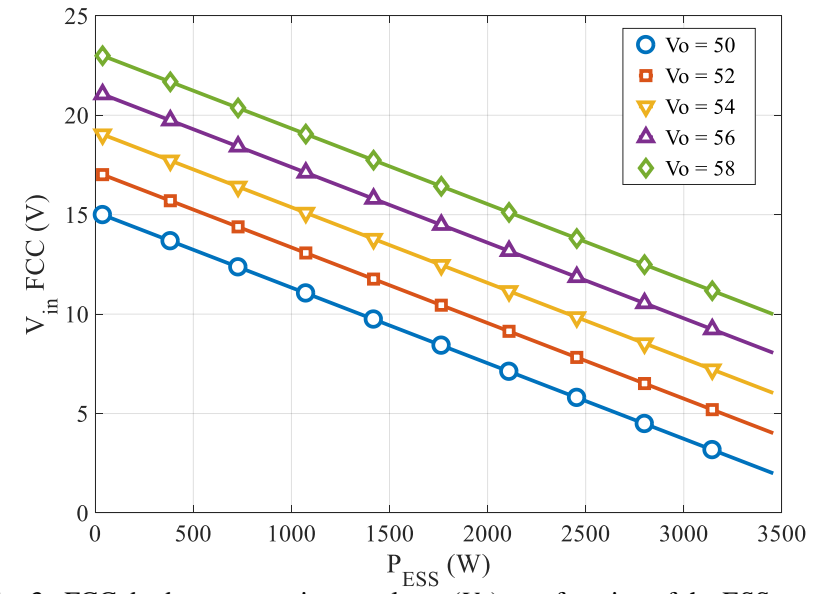

Fig. 3. FCC dc-dc converter input voltage $\left(V_{\text {in }}\right)$ as a function of the ESS power $\left(P_{E S S}\right)$ for different output voltages.

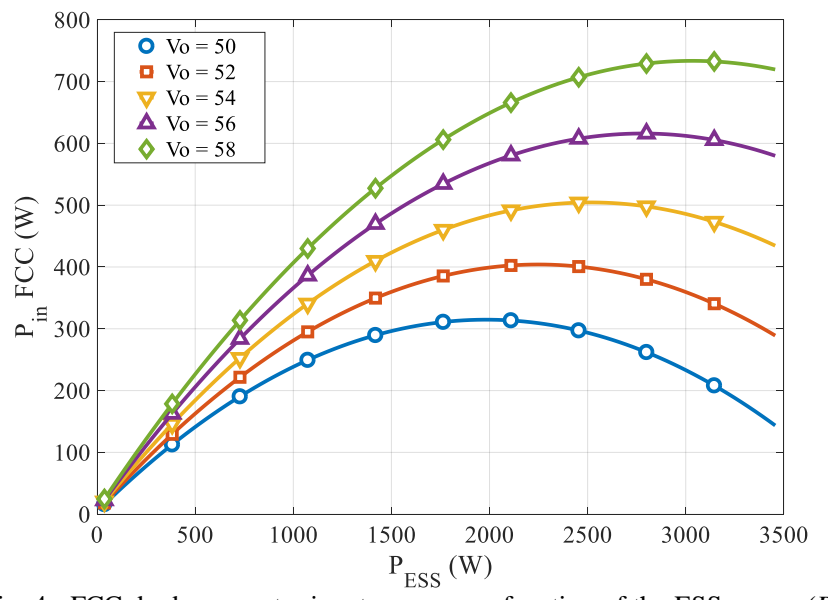

Fig. 4. FCC dc-dc converter input power as a function of the ESS power $\left(P_{E S S}\right)$ for different output voltages.

TABLE I

SySTEM SPECIFICATIONS

\begin{tabular}{|c|c|}
\hline $\bar{V}_{\text {bus }}$ & $50 \sim 58 \mathrm{~V}$ \\
\hline$V_{E S S}$ & $35 \sim 48 \mathrm{~V}$ \\
\hline$I_{E S S}$ & $1 \sim 72 \mathrm{~A}$ \\
\hline$V_{b u s}-V_{E s s}$ & $2 \sim 23 \mathrm{~V}$ \\
\hline ctrolyzer power, $P_{E S S}$ & $3456 \mathrm{~W}$ \\
\hline onverter power, $P_{d c-d c}$ & $733 \mathrm{~W}$ \\
\hline
\end{tabular}



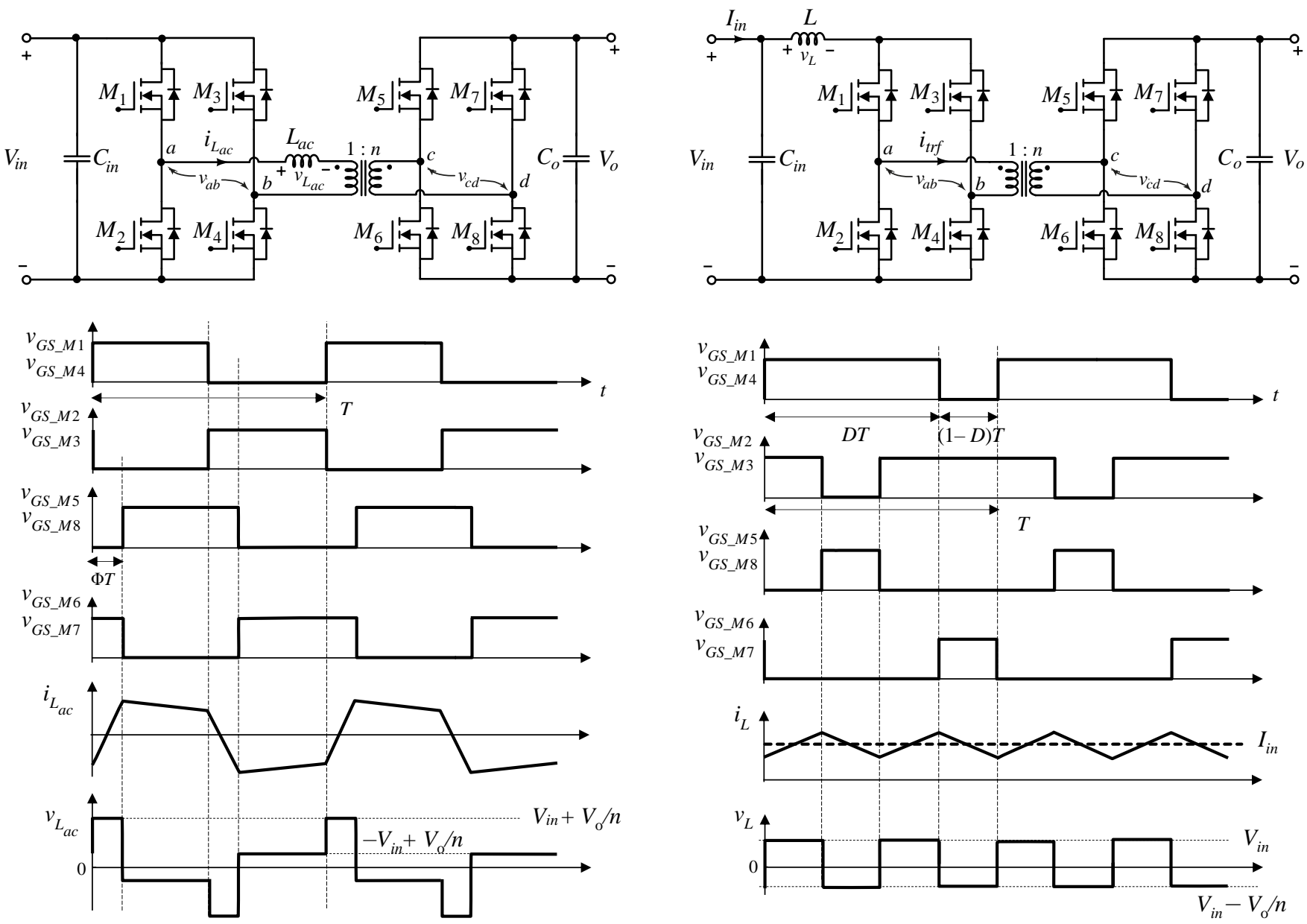

Fig. 5. DAB converter and its typical waveforms, top and bottom, respectively.

As shown in Table I, such an arrangement results in the maximum input power processed by the converter to be $P_{d c-d c}=$ $733 \mathrm{~W}$. Compared to the traditional parallel connection, where the converter would have been rated at the maximum ESS power of $P_{E S S}=3456 \mathrm{~W}$. Therefore, a reduction of nearly $80 \%$ of the required power of the $\mathrm{dc}-\mathrm{dc}$ converter is achieved, which considerably reduces the cost and weight of the dc-dc converter, as well as increasing the power density and efficiency of the system. For the fractional charging configuration the converter input voltage is defined as $V_{\text {in }}=V_{\text {bus }}-V_{E S S}$, and the converter output voltage is defined as $V_{o}$. Fig. 3 and Fig. 4 show the input voltage and input power of the dc-dc converter in FCC configuration, respectively, as a function of the power of the ESS, for different values of the output voltage. As it can be observed, the FCC configuration has the disadvantage of a large variation of the converter input voltage, which requires the selected topology to operate efficiently within a wide input to output voltage range. It is important to notice that the point at which the converter power is maximum, will not correspond with the maximum power of the ESS, as the characteristic electrolyzer stack curve will make the voltage at the input of the converter decrease as the power increases. It is also important to observe that the system needs to be designed so the amount of power processed by the converter tends to zero, thus, reducing

Fig. 6. IFBB converter and its typical waveforms, top and bottom, respectively.

the losses inserted in the system. Therefore, maximizing the efficiency of the direct power flow, which corresponds to the path to charge the ESS, will minimize the power processed by the dc-dc converter and maximize the efficiency of the system.

\section{COMPARING DAB AND IFBB CONVERTER BY COMPONENT STRESS FACTOR}

The topology selection is a key factor in achieving high efficiency, since it will determine the performance of the overall system. From the system specifications, it can be observed that the power stage presents a large input/output voltage variation. The challenge is to select a topology that can provide high power conversion efficiency over the whole operating range.

An analysis and review of high efficiency bidirectional dcdc converters with high voltage gain is performed [19]. Based on the analysis and the system specifications, the topology selection is narrowed down to two candidate topologies: dual active bridge (DAB) and isolated full bridge boost (IFBB) converter. The selection is performed based on complexity in terms of number of active switches, passive components and control. These components will affect the efficiency, cost and reliability of the entire system. Both DAB and IFBB topologies have been proved to achieve high efficiency, with a reduced component number (low complexity). Fig. 5 and Fig. 6 show the 
schematic of the DAB and IFBB topologies and their operating waveforms, respectively. As it can be observed, both converters present the same number of active switches and passive components. In the DAB, the power is delivered to the output through an ac inductor, whose charge and discharge is controlled with the phase-shift angle of the half bridge switching legs. In the IFBB converter, the control parameter is the duty cycle of the primary switches and the input inductor is the component that transfers the energy to the output port.

The analysis of the DAB and IFBB topologies is performed based on component stress factor (CSF) [20]. CSF is a derivation of the component load factors approach (CLF) [21]. CLF is a numerical method, which is calculated based on the components voltage and current stress and normalized to the processed power (volt-amp/watt figure), which makes the calculation dimensionless.

The approach of the CSF analysis is based on the assumption that the evaluated topologies have the same amount of resources: silicon for semiconductors, magnetic material and copper for windings and capacitor volume for energy storage/filter components. A weighing factor is applied to distribute the resources within the topology. The result of the CSF analysis provides an effective way to evaluate the losses in the individual components of the circuit, and consequently, an estimation of the converter performance. Therefore, the analysis gives a quantitative measure to compare the performance of different topologies for a specific application [22].

The CSF method adopts two assumptions in order to simplify the calculations, i.e., the power losses in the converter are neglected (efficiency 100\%) and the inductors are large enough to have no ripple current (square waveform).

The stress factor is calculated independently for each component: semiconductors (SCSF), windings (WCSF) and capacitors (CCSF), as shown in (1), (2), (3), respectively. The $\mathrm{CSF}$ is related to the power dissipated in the component. In the semiconductors, the conduction losses are calculated with the squared root mean square $(r m s)$ current through the device multiplied by the channel on-resistance of the switch. For a given die size, the channel on-resistance is proportional to the voltage rating to the power of 2.5 , higher voltage rating will result in a longer channel with smaller cross section. Taking the rated voltage squared gives a good approximation to relate the maximum voltage and the channel on-resistance. Therefore, SCSF is calculated with the breakdown voltage squared, times the rms current squared, and normalized to the square of the processed power, to provide a dimensionless quantity.

Regarding the calculation of the stress factor of magnetic components, to perform a fair comparison, each topology should have the same amount of copper volume, and hence, the same winding area. The windings losses in magnetic components are calculated with the rms current squared, times the winding resistance. The winding resistance is related to the number of turns and the cross-sectional area of the copper. The voltage applied to the windings is proportional to the number of turns. Therefore, the resistance will increase with the square of the number of turns, which is proportional to the voltage squared. The WCSF is then computed as the maximum voltage applied to the windings squared, multiplied by the rms current squared (2).
The maximum voltage applied to the winding is calculated as the average voltage applied to the winding over a period, as shown in (4).

The stress factor of capacitors is determined by the resistive losses due to the equivalent series resistance (ESR). The ESR is related to the capacitor volume, and the volume is proportional to the energy storage capacity, thus, the CCSF is calculated with the squared maximum voltage and the rms current as presented in (3).

$$
\begin{aligned}
S C S F_{i} & =\frac{\sum_{j} W_{j}}{W_{i}} \cdot \frac{V_{\max }{ }^{2} \cdot I_{r m s}{ }^{2}}{P_{i n}{ }^{2}} \\
W C S F_{i} & =\frac{\sum_{j} W_{j}}{W_{i}} \cdot \frac{V_{\max _{-} a v g}{ }^{2} \cdot I_{r m s}{ }^{2}}{P_{i n}{ }^{2}} \\
C C S F_{i} & =\frac{\sum_{j} W_{j}}{W_{i}} \cdot \frac{V_{\max }{ }^{2} \cdot I_{r m s}{ }^{2}}{P_{i n}{ }^{2}} \\
V_{\max \text { avg }} & =\sum_{i} D_{i} \cdot\left|V_{i}\right|
\end{aligned}
$$

The distribution of the resources is implemented by the term $\sum_{j} W_{j} / W_{i}$, which represents the weighting factor for component $i$, where $\sum_{j} W_{j}$ is the sum of the individual weights of all components of the same type and $W_{i}$ is the weight assigned to the component $i$. In the first iteration, the resources are distributed equally. Based on the results, the weight distribution can be adjusted. As a result, the component with higher CSF can be assigned with a larger amount of the resource in order to reduce the stress factor.

Once the stress factor for each component is calculated, the total CSF is computed as the sum of component stress factors of the same type as in shown in (5).

$$
\left\{\begin{array}{c}
S C S F=\sum_{i} S C S F_{i} \\
W C S F=\sum_{i} W C S F_{i} \\
C C S F=\sum_{S C S F_{i}}
\end{array}\right.
$$

From the procedure of the CSF calculation, we can observe that the analysis accounts for the conduction losses in switches, magnetic components and capacitors. However, it does not consider the switching losses in the semiconductors and the magnetic core losses. From the system specifications presented in Table I, the application under analysis is a low voltage, high current application; therefore, the conduction losses in the semiconductors will dominate over the switching losses. Regarding the magnetic components, the core losses are a function of the magnetic material, the volts-seconds, the peakto-peak ac flux density and the switching frequency. As discussed before, the system is characterized by a low input voltage to the dc-dc converter, and the switching frequency is limited to $50 \mathrm{kHz}$. Therefore, the CSF approach is considered a valid method to compare the topologies for the application under analysis. 
IEEE TRANSACTIONS ON INDUSTRY APPLICATIONS, VOL. X, NO. X, MONTH YEAR
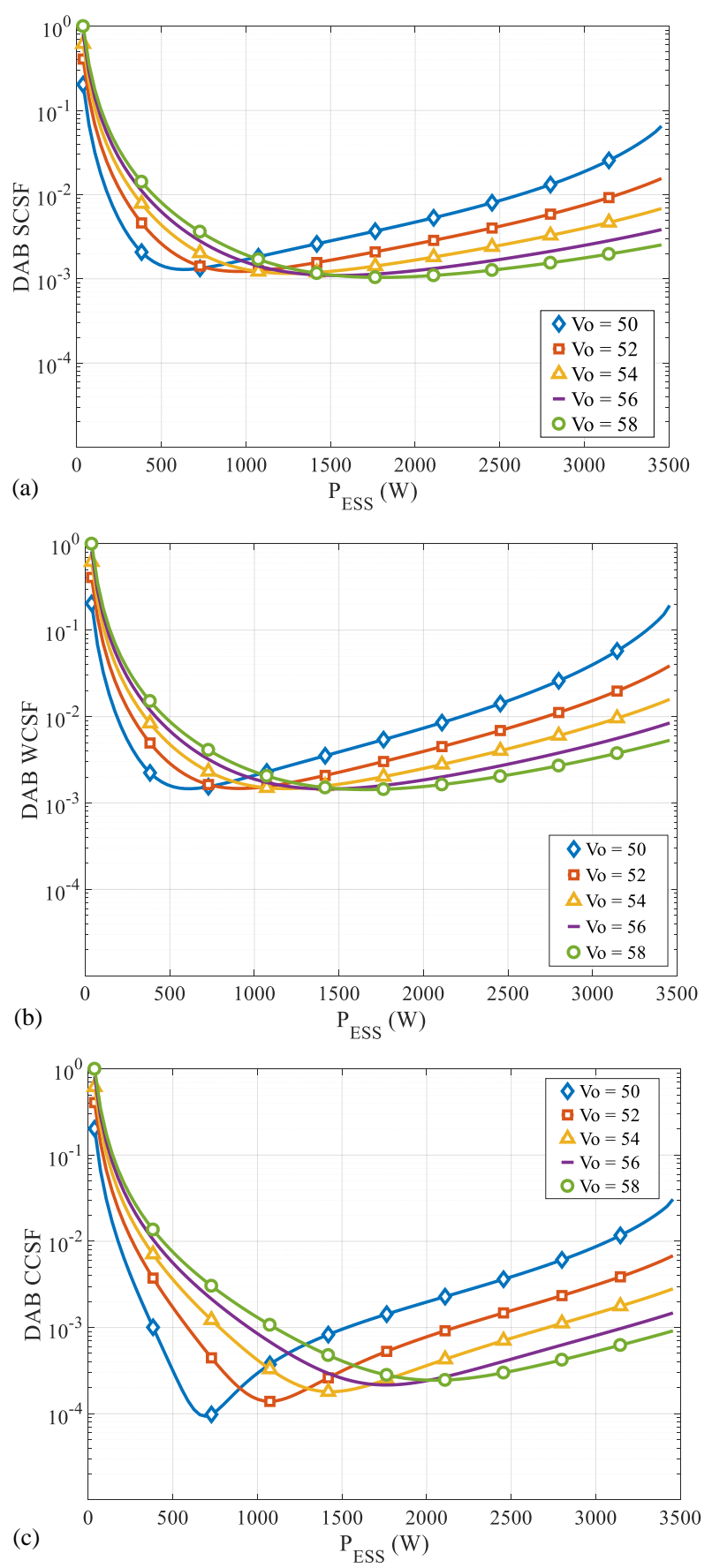

Fig. 7. CSF analysis. (a) DAB's SCSF, (b) DAB's WCSF, (c) DAB's CCSF,

Fig. 7 (a) to (f) shows the results of the CSF analysis for the DAB and the IFBB topologies for semiconductors (SCSF), windings (WCSF) and capacitors (CCSF), respectively. The graphs show the stress factor values as a function of the power of the ESS for different values of the output voltage. The CSFs are normalized to the maximum stress value, which occurs in the DAB topology. At low power levels the DAB converter present very high $\mathrm{CSF}$ in semiconductors, winding and capacitors compared to the IFBB topology. This is because the DAB topology presents a large rms circulating reactive current. At low
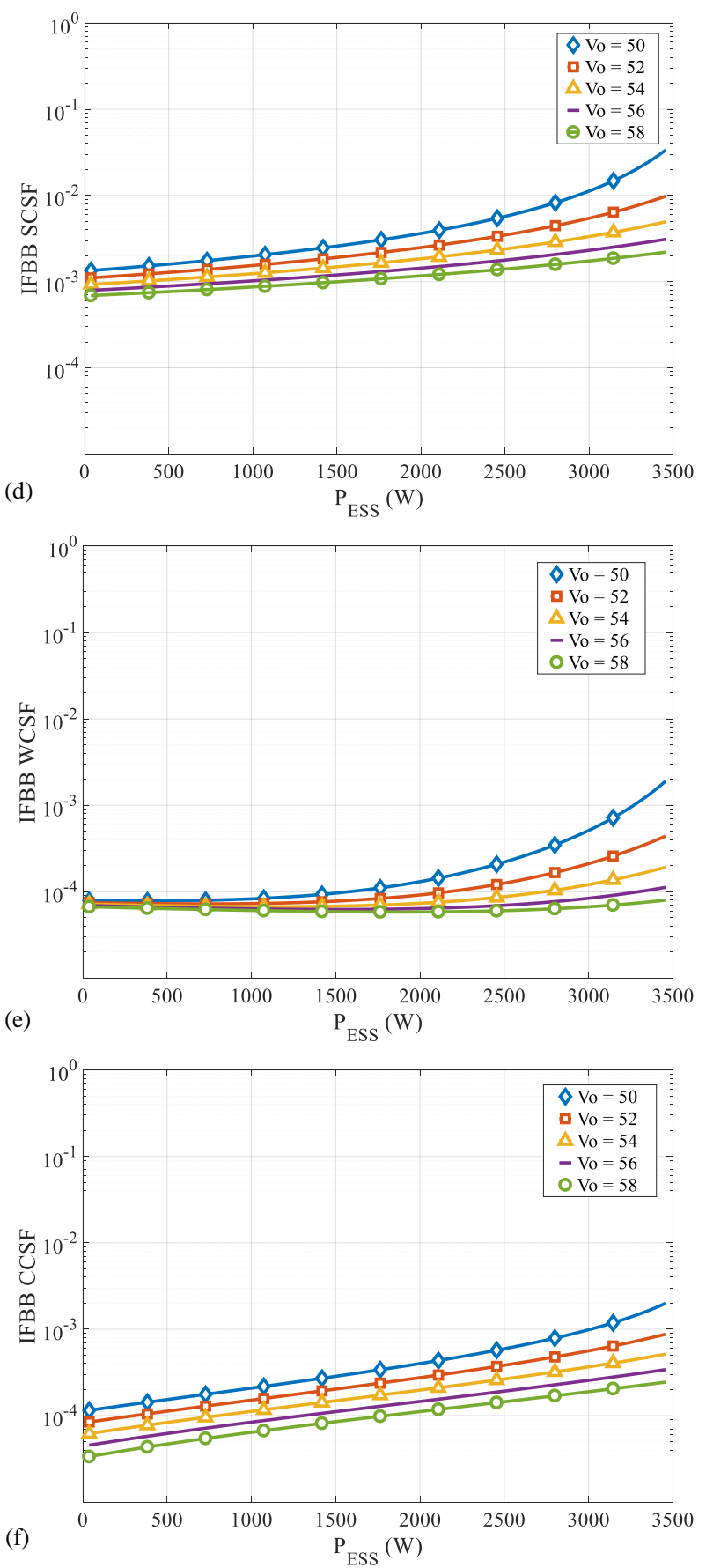

, (d) IFBB's SCSF, (e) IFBB's WCSF and (c) IFBB's CCSF.

power levels, the rms current is very large compared to the processed power, which results in large CSF values. As the power of the electrolyzer stack increases, the ratio of the rms current to the processed power is reduced and thus, the CSF. In the IFBB converter, the highest CSF occurs at the maximum ESS power level (maximum ESS current) and minimum output voltage. As we can observe from the SCSF, the DAB presents a minimum value for the different output voltages, which corresponds to the point where the converter reactive current is minimized. The IFBB presents higher stress as the input to 
output voltage transformation ratio is increased, which is an expected result from boost-derived topologies. The DAB therefore, shows a reduced SCSF compare to the IFBB, but only in a small range of the operating region. However, the WCSF for the DAB is significantly worse than that of the IFBB in all the operating range due to the increased voltage stress in the magnetic components and the alternating current nature in the resonant inductor. Based on the results of the CSF analysis, the IFBB converter is the selected topology to implement the energy storage system in FCC configuration.

\section{IFBB CONVERTER DESIGN}

A $750 \mathrm{~W}$ prototype of the IFBB converter is designed, constructed and tested in order to verify the theoretical analysis and test the FCC configuration.

\section{A. Magnetic components}

Due to the practical height constraint in the electrical power supply unit for the stack of electrolyzer cells, planar magnetic design for the inductor and the transformer is adopted. Planar magnetics offers low profile structure with high surface area and good thermal characteristics. Moreover, it helps implementing interleaving techniques to achieve low leakage inductance and ac resistance. However, in terms of loss, selecting PCB winding or wire-wound winding highly depends on required specifications as discussed in [23].

The IFBB inductor is designed for inductance of $L=2.4 \mu \mathrm{H}$, with the maximum current ripple of $\Delta i=25 \mathrm{~A}$ under the worst condition (maximum volt-sec). Three different core sizes and number of turns are compared as shown in Table II. From Table II, it can be observed that, for the same number of windings ( 3 turns), the loss efficiency $\left(P_{l o s s} / P_{d c-d c}\right)$ difference of the inductors with cores ELP43/10/28 and ELP58/11/38 is only $0.1 \%$. ELP43/10/28 (volume $=11500 \mathrm{~mm}^{3}$ ) has almost half of the volume of ELP58/11/38 (volume $=20800 \mathrm{~mm}^{3}$ ), which gives higher power density and lower price, therefore, this core is finally selected. The inductor is manufactured in a six layers PCB with $210 \mu \mathrm{m}$ (6 oz.) copper thickness. Two PCBs are stack in parallel in order to reduce the dc resistance.

The transformer is manufactured in an eight layers PCB with $210 \mu \mathrm{m}(6 \mathrm{oz}$.) copper thickness with the turns-ratio of 1:2. The primary winding (Prim) is formed by two turns in parallel, which are fully interleaved with four turns of the secondary winding, in a structure as shown in Fig. 8. Full interleaving winding technique is implemented in order to reduce the transformer leakage inductance, in this case $M=8$ in (6). Achieving a low leakage inductance is critical in full bridge boost configurations without any clamp circuit, because the energy stored in the leakage inductance will cause an overshoot in the primary MOSFETs. The measured transformer leakage inductance is $L i k$ $=19.4 \mathrm{nH}$. Full interleaving technique can also help reducing the ac resistance, as the magneto motive force (MMF) is always equal to one i.e. $m=1$ in (7)

$$
L_{l k} \approx \mu_{0} \frac{l_{w} h_{w} N^{2}}{3 b_{w} M^{2}}
$$

where $\mu_{0}$ represents permeability of free space, $l_{w}$ is mean turn length, $b_{w}$ is breadth of winding, $M$ is number of primary-
TABLE II

INDUCTOR DESIGN

\begin{tabular}{cccc}
\hline \hline Core & Winding & Current ripple & Loss \\
\hline \multirow{2}{*}{ ELP38/8/25 } & 2 turns & $\Delta \mathrm{I}=44.0 \mathrm{~A}$ & $3.4 \mathrm{~W}$ \\
& 3 turns & $\Delta \mathrm{I}=26.6 \mathrm{~A}$ & $4.3 \mathrm{~W}$ \\
\hline \multirow{2}{*}{ ELP43/10/28 } & 2 turns & $\Delta \mathrm{I}=36.0 \mathrm{~A}$ & $3.3 \mathrm{~W}$ \\
& 3 turns & $\Delta \mathrm{I}=22.3 \mathrm{~A}$ & $4.1 \mathrm{~W}$ \\
\hline \multirow{2}{*}{ ELP58/11/38 } & 2 turns & $\Delta \mathrm{I}=25.2 \mathrm{~A}$ & $2.9 \mathrm{~W}$ \\
& 3 turns & $\Delta \mathrm{I}=15.8 \mathrm{~A}$ & $3.6 \mathrm{~W}$ \\
\hline \hline
\end{tabular}

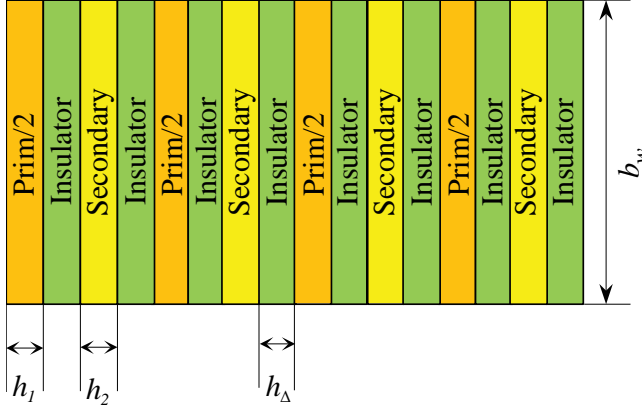

Fig. 8. Transformer winding structure.

secondary intersections and $N$ is number of winding turns.

$$
\frac{R_{a c}}{R_{d c}}=\varphi \frac{\sinh (2 \varphi)+\sin (2 \varphi)}{\cosh (2 \varphi)-\cos (2 \varphi)}+\frac{2\left(2 m^{2}-1\right)}{3} \varphi \frac{\sinh (\varphi)+\sin (\varphi)}{\cosh (\varphi)-\cos (\varphi)}(7)
$$

where $\varphi=h / \delta$, and $h$ and $\delta$ are height of conductor and penetration depth in material.

\section{B. Converter prototype}

Besides the magnetic components, the converter is designed with a 4-layer PCB and a special attention is paid to minimize the ac current loops i.e. the source and return paths are on top of each other. Due to the high current application, $140 \mu \mathrm{m} \mathrm{(4} \mathrm{oz)}$ PCB copper thickness is used in order to minimize the resistive losses [24].The main converter components are listed in Table III. The design is based on Silicon ( $\mathrm{Si}$ ) MOSFETs with low RDS on-resistance in order to reduce the conduction losses. DirectFET technology from Infineon is selected, which provides low package inductance and maximized thermal transfer due to copper drain clip. The high rms current on the IFBB primary side, which is around Irms_prim_Mos $=40$ A, will cause high conduction losses, therefore, primary MOSFETs with very low onresistance are selected, $R D S=0.34 \mathrm{~m} \Omega$ at $V_{G S}=10 \mathrm{~V}$. The maximum rms current on the secondary side is $I_{r m s_{-} s e c \_M O S}=15$ A, which allows to select devices with higher on-resistance than in the primary side. The converter switching frequency is $f_{s w}=$ $50 \mathrm{kHz}$, to limit the switching losses.

The control law is implemented in a digital signal processor (DSP) TMS320F2808 from Texas Instruments. The reading of the inductor current is performed with a high precision HallEffect current sensor, which inserts an extremely low resistance of $R_{\text {sens }}=0.1 \mathrm{~m} \Omega$. Fig. 9 shows the experimental prototype of the IFBB converter. The primary and secondary MOSFETs are placed on the bottom side of the PCB, in order to transfer the heat to the heat sink through an isolated gap pad material with a thermal conductivity of $4.0 \mathrm{~W} / \mathrm{mK}$. 
IEEE TRANSACTIONS ON INDUSTRY APPLICATIONS, VOL. X, NO. X, MONTH YEAR

TABLE III

IFBB CONVERTER COMPONENTS

\begin{tabular}{cc}
\hline \hline$M_{1} \sim M_{4}$ & IRL7472L1 \\
$M_{5} \sim M_{8}$ & AUIRF7759L2 \\
ISO gate drivers & SI8235AB-D-IS1 \\
Transformer & $1: 2$, EILP43/10/28, Ferrite N87 \\
Inductor & $2.3 \mu \mathrm{H}$, EILP43/10/28, Ferrite N87 \\
Capacitors $C_{i n}$ & $20 \times 10 \mu \mathrm{F} \mathrm{50V} \mathrm{X7R}$ \\
Capacitors $C_{\text {out }}$ & $20 \times 10 \mu \mathrm{F} 100 \mathrm{~V}$ X7S \\
Current sensor & ACS770LCB-100B \\
Switching frequency & $f_{s w}=50 \mathrm{kHz}$ \\
Digital controller & TMS320F2808 DSP \\
\hline \hline
\end{tabular}

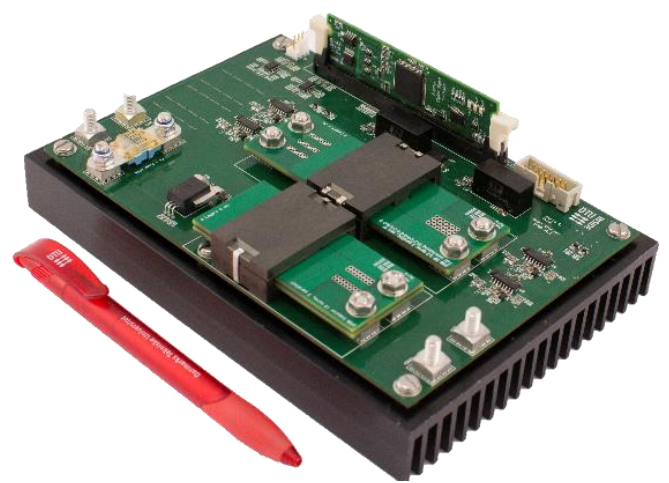

Fig.9. IFBB converter prototype.

\section{EXPERIMENTAL RESULTS}

The experimental test is carried out with two steps: the constructed IFBB converter is tested in the laboratory firstly to verify the design validity. Then the IFBB converter is connected with a real $3.5 \mathrm{~kW}$ stack of alkaline electrolyzer cells in the manner of the proposed fractional power charging configuration shown in Fig. 1, and therefore the entire system test is accomplished.

\section{A. IFBB converter test}

For the experimental test of the IFBB converter, the behavior of the electrolyzer stack is simulated with an electronic load in series with a power resistor. The electronic load is configured as a constant voltage source and will set the starting point of the characteristic V-I curve shown in Fig. 3. The power resistor $(R$ $=0.185 \Omega$ connected in series, will provide the slope of the $\mathrm{V}$-I curve as the IESS current increases. Fig. 10 shows the steady state waveforms of the IFBB converter, where $v_{G S}$ is the gate-source voltage of the low-side switch $S_{4}, i_{L}$ is the inductor current, and $v_{a b}$ and $i_{t r f}$ represent the transformer voltage and current as denoted in Fig.6. Fig. 10 (a) shows the converter operating at $V_{o}$ $=50 \mathrm{~V}, V_{E S S}=38 \mathrm{~V}, I_{E S S}=13 \mathrm{~A} V_{\text {in }}=12 \mathrm{~V}, P_{E S S}=594 \mathrm{~W}, P_{d c-d c}$ $=156 \mathrm{~W}$. In this conditions, the duty cycle $D$ is approx. $75 \%$. Fig. 10 (b) shows the IFBB converter waveforms at the system maximum power level i.e. the electrolyzer is charging at the maximum current. The converter operating conditions are $V_{o}=$ $50 \mathrm{~V}, V_{E S S}=48 \mathrm{~V}, I_{E S S}=72 \mathrm{~A}, V_{i n}=2 \mathrm{~V}, P_{E S S}=3456 \mathrm{~W}, P_{d c}-d c$ $=144 \mathrm{~W}$ and the converter's duty cycle is maximum $D=99 \%$.
As it can observed the inductor current ripple reduces as the input voltage of the converter decreases. However, the peak current on the transformer secondary side increases due to the reduced conducting time of the secondary MOSFETs. Fig. 11 shows an enlarged portion of the steady state waveforms when the converter operates at maximum duty cycle (Fig. 10 (b)). As it can be observed, the voltage across the transformer does not clamp, which indicates that there is no avalanche mode operation of the MOSFETs primary side, which proves the low leakage inductance design of the transformer, thus, no snubber components are required. Fig. 12 presents a thermal image of the IFFB converter operating at the worst conditions, which are minimum input voltage and maximum input current, while the system is working at the maximum power level $P$ ESS $=3456 \mathrm{~W}$. The thermal image shows a maximum temperature of $98.9^{\circ} \mathrm{C}$. As the input voltage decreases, the converter current stress on the secondary side reduces, while it increases on the primary side, therefore, the highest temperature appears at the converter primary side.

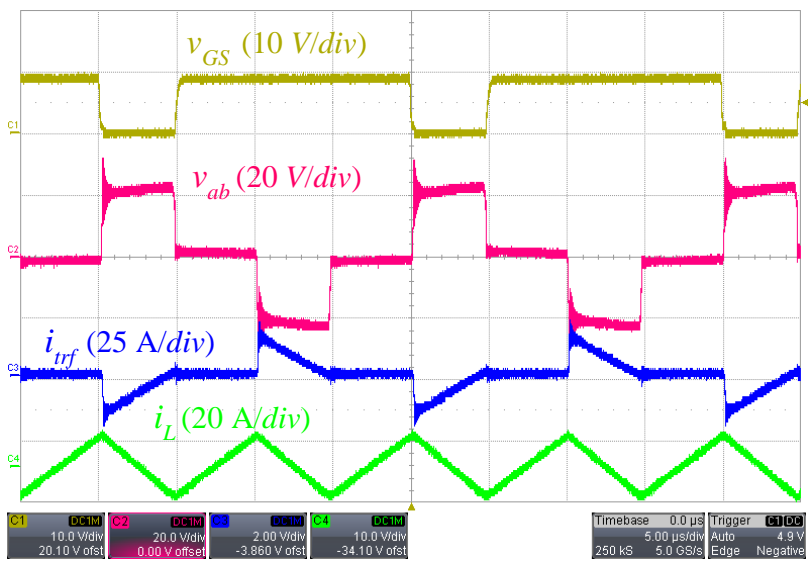

(a)

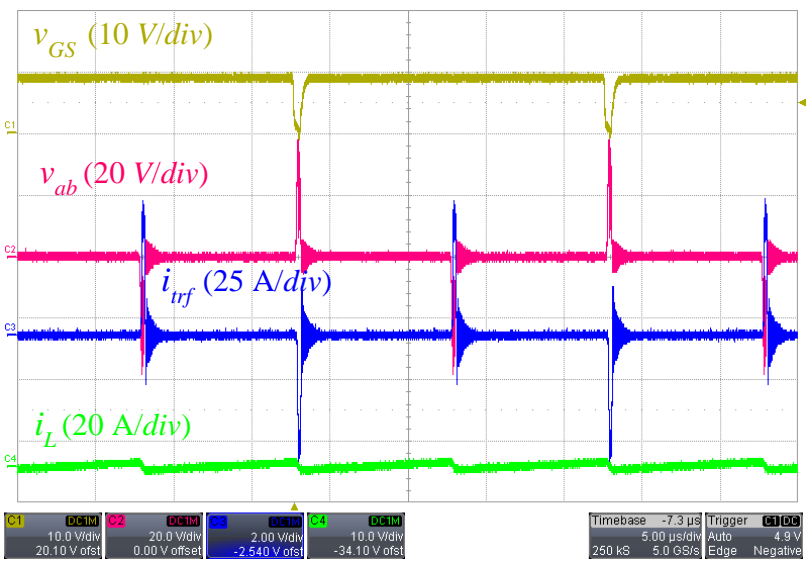

(b)

Fig. 10. IFBB operating waveforms, from top to bottom: primary gate-to-source voltage $(10 \mathrm{~V} / \mathrm{div})$; voltage across the transformer primary side $(20 \mathrm{~V} / \mathrm{div})$ transformer secondary side ac current (25 A/div) Rogowski coil (20 mV/A); inductor ac current (20 A/div) Rogowski coil (100 mV/A). Time scale $5 \mu \mathrm{s} /$ div. 


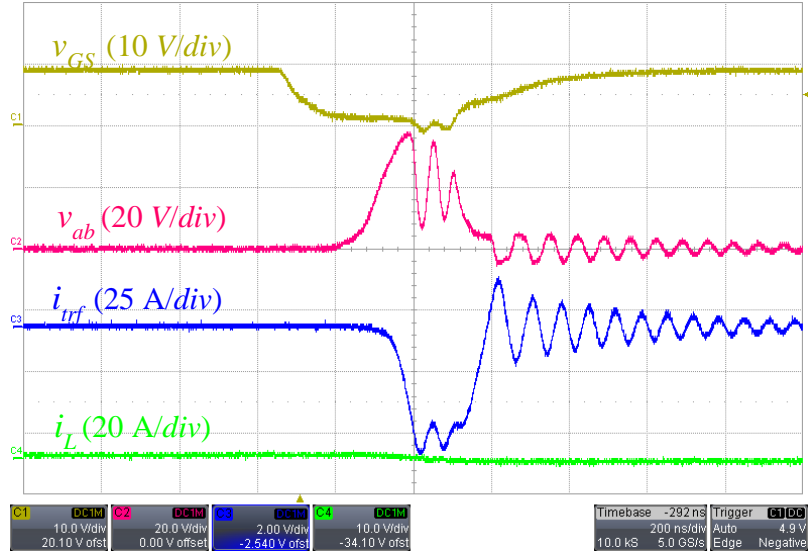

Fig. 11. Enlarged IFBB operating waveforms from top to bottom: primary gateto-source voltage $(10 \mathrm{~V} / \mathrm{div})$; voltage across the transformer primary side (20 $\mathrm{V} /$ div); transformer secondary side ac current (25 A/div) Rogowski coil (20 $\mathrm{mV} / \mathrm{A})$; inductor current ac (20 A/div) Rogowski coil (100 mV/A). Time scale $200 \mathrm{~ns} /$ div.

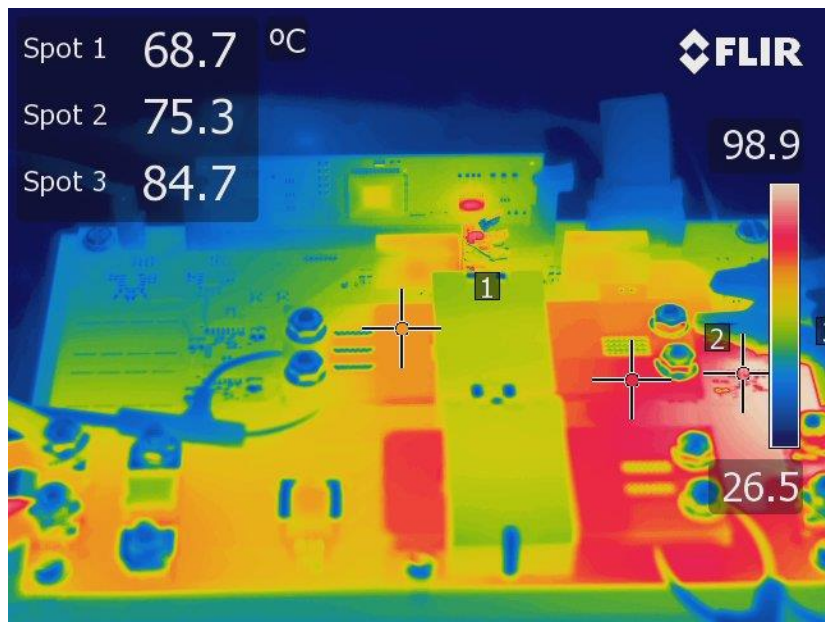

Fig. 12. Thermal image of the IFBB converter operating at the electrolyzer stack maximum power $P_{\mathrm{ESS}}=3456 \mathrm{~W}$.

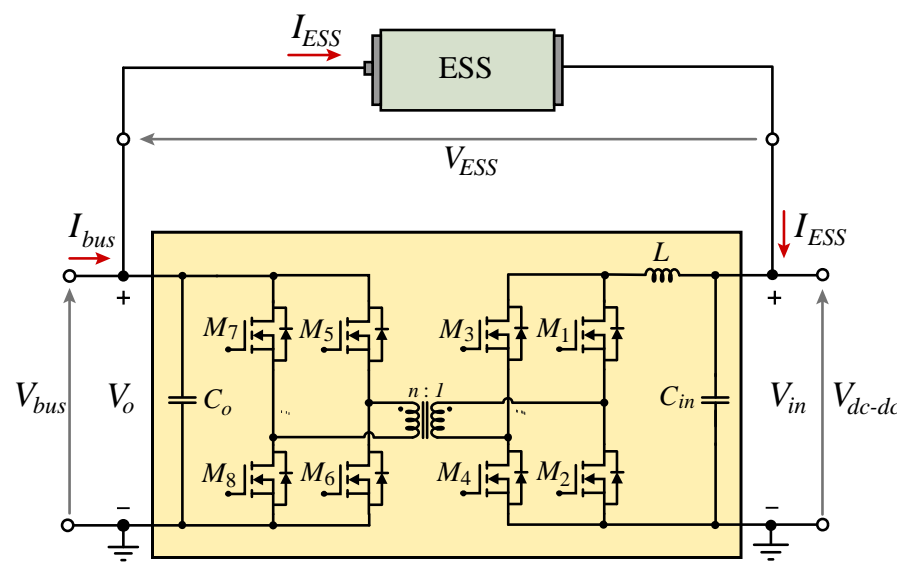

Fig. 13. Block diagram of the integration test.

\section{B. System test}

For system test, the tested IFBB converter is inserted into the proposed fractional charging configuration, as shown in Fig. 13.

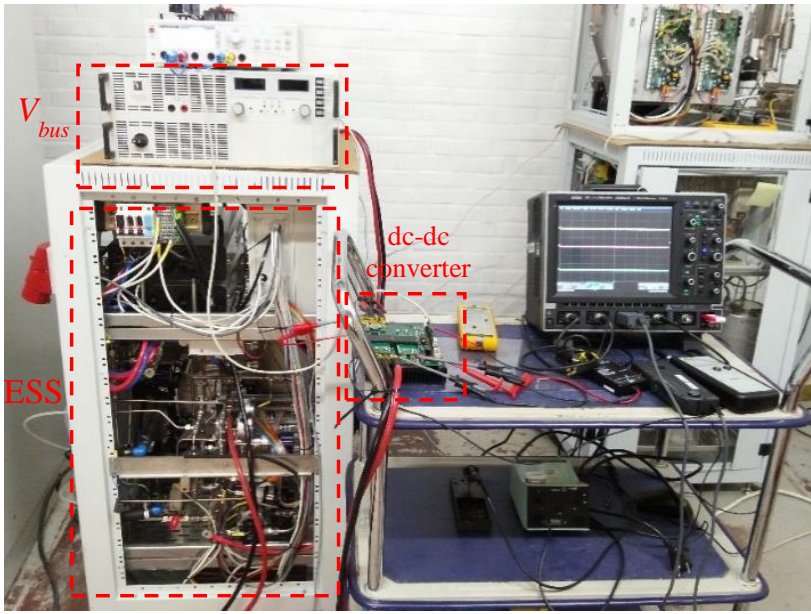

Fig. 14. System test setup.

The IFBB's primary side is connected in series with the ESS This series configuration allows for the converter to control the current flow through the ESS, and consequently its power, by controlling the IFBB converter input current. If the input port $V_{\text {in }}$ is shorted, i.e. the switches $M_{1} \sim M_{4}$, or $M_{1}$ and $M_{2}$, or $M_{3}$ and $M_{4}$ are always kept ON, the ESS will be directly connected in parallel with the dc bus, $V_{\text {bus }}$. However, if the input port $V_{\text {in }}$ is open, i.e. the switches $M_{1} \sim M_{4}$, or $M_{1}$ and $M_{3}$, or $M_{2}$ and $M_{4}$ are always kept OFF, there will be no current flowing through the ESS. Finally, a real $3.5 \mathrm{~kW}$ stack of alkaline electrolyzer cells, as the ESS for hydrogen production and the corresponding tests are then carried out. Fig. 14 shows the system test setup, where the dc bus voltage, $V_{\text {bus }}$, the electrolyzer stack, and the dc-dc converter are highlighted. The converter efficiency and the system efficiency have the relationship expressed as (8) and (9).

$$
\begin{gathered}
\eta_{d c-d c}=\frac{P_{o_{d c-d c}}}{P_{i n_{d c}-d c}} \cdot 100 \%=\frac{P_{o_{d c}-d c}}{P_{i n_{d c}-d c}+P_{l o s s}} \cdot 100 \% \\
\eta_{s y s}=\frac{P_{E C}}{P_{E C}+P_{l o s s}} \cdot 100 \%
\end{gathered}
$$

As it can be observed in Fig. 15, the highest efficiency of the system occurs at the worst conditions of the dc-dc converter (dcdc converter input voltage $V_{i n}=2 \mathrm{~V}$, and electrolyzer current $I_{E S S}$ $=72 \mathrm{~A})$. It is because the IFBB converter is processing the lowest amount of power $\left(P_{d c-d c}=144 \mathrm{~W}\right)$ compared to the system output power $\left(P_{E S S}=3456 \mathrm{~W}\right)$. The highest measured system efficiency is $\eta_{\text {sys }}=98.2 \%$.

Fig. 16 (a) and (b) show a load step from 0 to $6 \mathrm{~A}$, positive and negative, respectively. These waveforms correspond to the start-stop test of the converter. First, we can see that the electrolyzer current is fully controlled and it presents a critically damped response without overshoot. The settling time is approximately $5 \mathrm{~ms}$ for the positive current step, and $2 \mathrm{~ms}$ for the negative load step. Second, due to the V-I characteristics of the electrolyzer stack, the system can still operate at no current $I_{E S S}$, by controlling the corresponding switches $M_{1} \sim M_{4}$ to open the IFBB converter input. Furthermore, from the start-stop test, it can also verify the effective fault protection and the converter can quickly cut off the electrolyzer current. 


\section{IEEE TRANSACTIONS ON INDUSTRY APPLICATIONS, VOL. X, NO. X, MONTH YEAR}

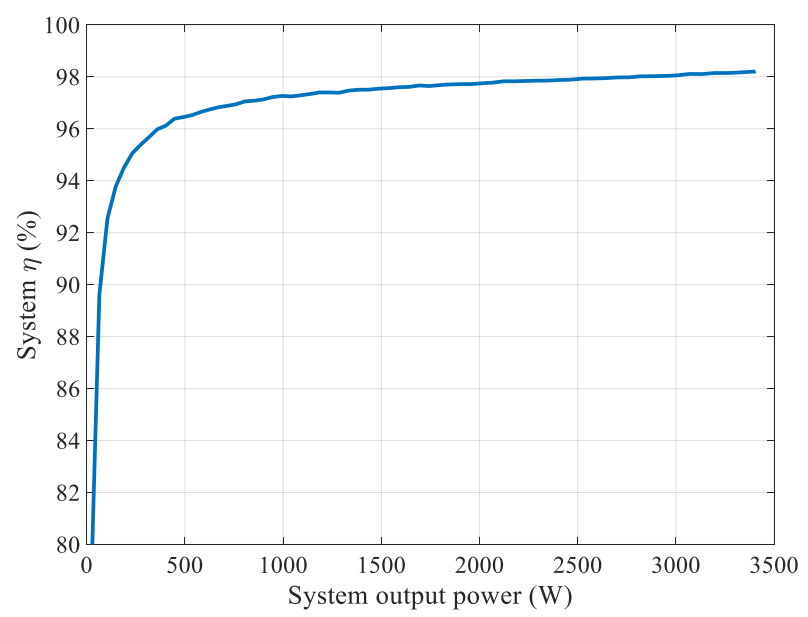

Fig. 15. Measured system efficiency $\eta_{s y s}$.

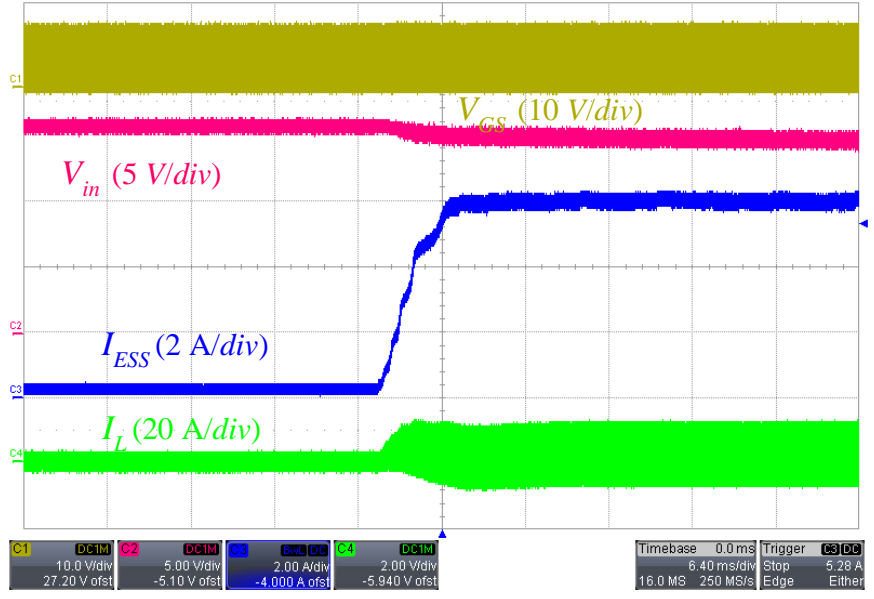

(a)

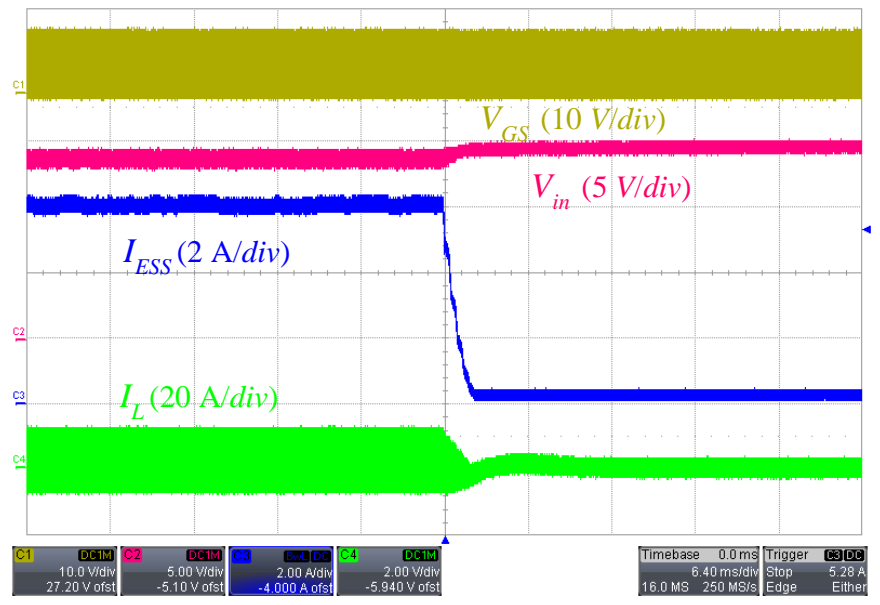

(b)

Fig. 16. System test of load step response. (a) positive step and (b) negative step. From top to bottom: converter input voltage (10 V/div); dc-dc converter input voltage $V_{\text {in }}(5 \mathrm{~V} / \mathrm{div})$; electrolyzer stack current $I_{E S S}(2 \mathrm{~A} / \mathrm{div})$, inductor ac current (20 A/div), Rogowski coil (100 mV/A). Time scale $6.4 \mathrm{~ms} / \mathrm{div}$.

\section{CONCLUSION}

This paper presents a fractional charging converter (FCC) configuration, which can use a $750 \mathrm{~W}$ dc-dc converter to regulate an approx. $3.5 \mathrm{~kW}$ electrolyzer stack to generate hydrogen. The analytical comparison of dc-dc topologies in such proposed configuration was carried out. Selecting the most appropriate topology for a specific application is crucial in achieving high efficiency. Although the two analyzed converters present the same number of active switches and passive components, the CSF analysis shows a big difference of the converters' performance for the given configuration. Based on the analysis, an IFBB converter is designed and tested. Experimental results shows the converter can handle the maximum system power level with a reduction of $80 \%$ of the power rating compared to traditional load connection, which achieves a high reduction on the converter size, weight and price. However, due to the series connection, there is no galvanic isolation between the input power supply and electrolyzer stack, which may introduce other issues for some applications and thereby needs investigate in the future research work.

\section{REFERENCES}

[1] J. P. Barton and D. G. Infield, "Energy storage and its use with intermittent renewable energy," IEEE Trans. Energy Convers., vol. 19, no. 2, pp. 441-448, 2004.

[2] D. Stenclik, P. Denholm, and B. Chalamala, "Maintaining Balance: The Increasing Role of Energy Storage for Renewable Integration," IEEE Power Energy Mag., no. december, pp. 31-39, 2017.

[3] C. Baumann, R. Schuster, and A. Moser, "Economic potential of power-to-gas energy storages," in International Conference on the European Energy Market, EEM, 2013.

[4] R. R. Dickinson, N. Lymperopoulos, A. L. Duigou etc., "Powerto-hydrogen and hydrogen-to-X pathways: Opportunities for next generation energy systems," 14th International Conference on the European Energy Market (EEM), 2017.

[5] J. Koponen, V. Ruuskanen, A. Kosonen, M. Niemela, and J. Ahola "Effect of Converter Topology on the Specific Energy Consumption of Alkaline Water Electrolyzers," Power Electron. IEEE Trans, 2018.

[6] F. Blaabjerg, Z. Chen, and S. B. Kjaer, "Power Electronics as Efficient Interface in Dispersed Power Generation Systems," Power Electron. IEEE Trans., vol. 19, no. 5, pp. 1184-1194, Sep. 2004.

[7] Z. Zhang, O. C. Thomsen, M. A. E. Andersen, "Optimal design of a push-pull-forward half-bridge (PPFHB) bidirectional DC-DC converter with variable input voltage," IEEE Trans. Ind. Electron., vol. 59, no. 7, pp. 2761-2771, 2010.

[8] Z. Chen, J. M. Gurrero, and F. Blaabjerg, "A Review of the State of the Art of Power Electronics for Wind Turbines," Power Electron. IEEE Trans., vol. 24, no. 8, pp. 1859-1875, Aug. 2009.

[9] M. Button, "An Advanced Photovoltaic Regulator Module Array," in IECEC 96. Proceedings of the 31st Intersociety Energy Conversion Engineering Conference, 1996, pp. 519-524.

[10] M. Madsen, M. Kovacevic, J. D. Mønster etc., "Input-ouput rearrangement of isloated converters," IEEE Power and Energy Conference at Illinois, Champaign, IL, Feb. 2015.

[11] M. Kasper, D. Bortis and J. W. Kolar, "Classification and Comparative Evaluation of PV Panel-Integrated DC-DC Converter Concepts," IEEE Transactions on Power Electronics, vol. 29, no.5, pp.2511-2562, May 2014.

[12] H. Jeong, H. Lee, Y.-C. Liu and K. A. Kim, "Review of Differential Power Processing Converter Techniques for Photovoltaic Applications," IEEE Transactions on Energy Conversion, vol.34, no.1, pp.351-360, Mar. 2019.

[13] N. Kim and B. Parkhideh, "PV-battery series inverter architecture: a solar inverter for seamless battery integration with partial power dc-dc optimizer," IEEE Transactions on Energy Conversion PP(99):1-1, Oct. 2018. 


\section{IEEE TRANSACTIONS ON INDUSTRY APPLICATIONS, VOL. X, NO. X, MONTH YEAR}

[14] V. M. Iyer, S. Gulur, G. Gohil and S. Bhattacharya, "Extrme fast charging station architecture for electric vehicles with partial power processing," IEEE APEC, 2018.

[15] H. Lee and K. A. Kim, "Design consideration for parallel differential power processing converters in a photovoltaicpowered wearable application," Energies, vol. 11, 2018.

[16] F. Xue, R. Yu, and A. Huang, "Fractional Converter for High Efficiency High Power Battery Energy Storage System," in 2017 IEEE Energy Conversion Congress and Exposition (ECCE), 2017, pp. 5144-5150.

[17] K. T. Manez, A. Anthon and Z. Zhang, "High Efficiency Power Converter for a Doubly-fed SOEC/SOFC System,"APEC, pp. $1235-1242,2016$.

[18] M. C. Mira, Z. Zhang and M. A. E. Andersen, "Analysis and Comparison of $\mathrm{dc} / \mathrm{dc}$ Topologies in Partial Power Processing Configuration for Energy Storage Systems," in Proc. of IEEE International Power Electronics Conference (ECCE-Asia), pp. 1351-1357, 2018.

[19] K. L. Jørgensen, M. C. Mira, Z. Zhang, and M. A. E. Andersen, "Review of High Efficiency Bidirectional dc-dc Topologies with
High Voltage Gain," 52nd International Universities Power Engineering Conference (UPEC), 2017.

[20] E. Wittenbreder, "Topology Selection by the Numbers," Technical Witts, Inc., pp. 1-19, 2006.

[21] B. Carsten, "Coverter Component Load Factors; A Performance Limitation of Various Topologies," in International PCI Conference on Power Conversion, 1988, pp. 31-48.

[22] Z. Zhang, M. C. Mira, and M. A. E. Andersen, "Analytical Comparison of Dual-Input Isolated dc-dc Converter with an ac or dc Inductor for Renewable Energy Systems," ECCE-Asia, pp. 659-664, 2017

[23] T. Kanstad, M. K. Lillholm, Z. Zhang, "Highly Efficient EV Battery Charger Using Fractional Charging Concept with SiC Devices," IEEE-APEC 2019.

[24] M. Nymand and M. A. E. Andersen, "High-efficiency isolated boost DCDC converter for high-power lowvoltage fuel-cell applications," IEEE Trans. Ind. Electron., vol. 57, no. 2, pp. 505$514,2010$. 